\title{
Attitudes of U.S. Hispanic and non-Hispanic women toward congenital CMV prevention behaviors: a cross sectional study
}

\author{
Rosemary Thackeray ${ }^{1 *} \mathbb{D}$, Brianna M. Magnusson' ${ }^{1}$ Erica Bennion ${ }^{1}$, Natalia N. Nielsen ${ }^{1}$ and Ryan J. Bailey ${ }^{2}$
}

\begin{abstract}
Background: Congenital cytomegalovirus (CMV) infection is the most common intrauterine infection. The only way to protect against congenital CMV infection is to practice CMV prevention behaviors. CMV seroprevalence rates are high in Hispanic women. It is unknown whether communication strategies should differ by ethnicity. The purpose of this study was to understand differences between U.S. Hispanic and non-Hispanic women's attitudes toward CMV prevention behaviors and examine the relationship between perceived subjective norms and these attitudes.

Methods: This was a cross-sectional study using an online panel. Participants were U.S. women of childbearing age. The dependent variable was attitude toward practicing CMV prevention behaviors, specifically avoiding sharing cups, food, and utensils with a child and not kissing a child on the lips.

Results: Among 818 women (50\% Hispanic), 16.8\% of Hispanic women and 9.7\% of non-Hispanic women ( $p=0.002$ ) reported familiarity with CMV. Attitudes toward CMV prevention through avoiding sharing behaviors $\left(M_{\text {Hispanic }}=5.55\right.$ vs. $\left.M_{\text {non-Hispanic }}=5.20 ; p=0.002\right)$ and not kissing a child on the lips ( $M_{\text {Hispanic }}=4.80$ vs. $\left.M_{\text {non-Hispanic }}=4.21 ; p=0.001\right)$ were positive for both ethnicities, but higher for Hispanic women. Hispanic women $(M=5.11)$ reported higher perceived behavioral control for avoiding kissing a child on the lips than non-Hispanic women $(M=4.63 ; p=0.001)$. Hispanic women who were U.S. born or spoke English primarily more frequently kissed a child on the lips or engaged in sharing behaviors. Additionally, those who spoke Spanish mostly held more positive attitudes toward not kissing on the lips. Significant predictors for more positive attitudes toward CMV prevention behaviors were associated with perceived subjective norms, perceived behavioral control and pre-survey participation in risk behaviors.

Conclusions: Hispanic women have more positive attitudes toward CMV prevention behaviors than non-Hispanic women, however in regression models other factors are more important predictors of positive attitudes than ethnicity. In developing strategies to encourage women to practice CMV prevention behaviors, a focus on further understanding and increasing subjective norms and perceived control over those behaviors may be warranted.
\end{abstract}

Keywords: Cytomegalovirus, Attitudes, Hispanic, Prevention, Subjective norms, Women

\section{Background}

Cytomegalovirus (CMV) is a prevalent virus, affecting people of all ages. One-third of U.S. children are CMV infected by age 5 and $>50 \%$ of adults become infected by age 40 [1]. Following primary infection, reactivation or reinfection may occur. For the majority of healthy persons, CMV results in asymptomatic or non-specific infection of mild severity and short duration [2].

\footnotetext{
* Correspondence: rosemary_thackeray@byu.edu

'Department of Health Science, Brigham Young University, Provo, UT, USA Full list of author information is available at the end of the article
}

However, CMV contracted or reactivated during the preor peri-conception periods or during pregnancy can result in congenital CMV infection [3].

Congenital CMV infection is the most common intrauterine infection with an estimated birth prevalence of $0.64 \%$ [4]. An estimated 13\% of CMV infected infants are born with apparent illness [5]. Approximately half $(40-58 \%)$ of surviving symptomatic and $13.5 \%$ of asymptomatic infants experience long-term sequelae [5]. Complications of congenital CMV infection include hearing loss, vision loss,

(c) The Author(s). 2018 Open Access This article is distributed under the terms of the Creative Commons Attribution 4.0 International License (http://creativecommons.org/licenses/by/4.0/), which permits unrestricted use, distribution, and 
premature birth, damage to the internal organs, growth restriction, microcephaly, intellectual disability, poor motor control, and death [5].

CMV is transmitted through contact with bodily fluids including urine and saliva. Infection during pregnancy is most likely to occur through sexual contact or contact with young children [6]. Young children shed the virus more abundantly and for longer periods than do infected adults [7-9]. As such, contact with young children's urine or saliva increases the risk of transmission. A quarter of parents of young children with CMV viral shedding seroconvert within a year [7].

To date, no licensed CMV vaccine is available. As such, behavioral modification is the only intervention available to reduce pregnant women's exposure to CMV and thus reduce the risk of babies being born with CMV. Recommended behavioral changes focus on limiting contact with children's urine or saliva by avoiding sharing cups, utensils, or food with children, washing hands following diaper changes, and not putting a child's pacifier in your mouth [10]. Evidence suggests that these behaviors may result in significant reduction in CMV seroconversion rates [11].

U.S. Hispanics ages 6-49 years have nearly twice the IgG seroprevalence for CMV compared to non-Hispanic whites $(76.9 \%$ vs. $39.5 \%)$ [12]. Similarly, $31 \%$ of U.S. Hispanic children aged $1-5$ years compared to $11 \%$ of non-Hispanic white children are seropositive for CMV IgG [12]. These demographic differences in CMV prevalence suggest the need for CMV prevention messages targeting higher risk persons [13]. However, none of the extant literature has examined differences between demographic groups that could inform communication.

The primary purpose of this study was to understand U.S. Hispanic women's attitudes toward CMV prevention behaviors and how these attitudes may differ those of non-Hispanic women. Additionally, we examined the relationship between two additional variables that, along with attitudes, are theorized to predict behavioral intention: subjective norms and perceived behavioral control [14, 15]. Subjective norms reflect whether friends, family and peers approve or disapprove of a behavior [14]. Perceived behavioral control represents the degree to which the person believes they have the ability to take action to perform the behavior [14]. We also examined the influence of past frequency of engaging in CMV prevention behaviors. Because Hispanic seroprevalance is high, it is thought that Hispanics may engage in these behaviors at different rates than non-Hispanic women. Additionally, a person's background experience, in this case, frequency of practicing the prevention behaviors, may interact with subjective norms, perceived behavioral control and attitudes to influence intention [14].
Prior research indicates that the majority of women regularly perform hand hygiene and few women regularly put a child's pacifier in their mouth $[16,17]$. For this reason, this paper focuses on the less practiced CMV prevention behaviors of not sharing food, cups, and utensils with children and not kissing children on the lips.

\section{Methods}

\section{Study design and participants}

This cross-sectional study included U.S. Hispanic and non-Hispanic women 18-40 years of age, with a child $\leq 5$ years of age living at home. Women who had ever worked as a health care provider or had a child with a diagnosed disability were excluded as both were hypothesized to have CMV knowledge that differ from those of the general population. Research participants were existing members of Survey Sampling International's (SSI) Hispanic or standard market research online panel. SSI randomly selected participants who, based on their panel profile, were highly likely to qualify for participation in the study. Completion of the survey indicated their consent. The Brigham Young University institutional review board approved the study. The survey was conducted in English. SSI indicated that all participants join their panel and complete surveys in English. To estimate differences in the proportion of women who know about CMV we needed a sample size of 350 in each group [18]. This calculation was based on a desired precision of $5 \%$ and previous research that indicated the proportion of women who knew about CMV was $12 \%$. This also provided adequate sample to compare means in attitudes scores between the two groups.

\section{Instrumentation}

The dependent variable was attitude toward practicing the CMV prevention behaviors, specifically avoiding sharing cups, food, and utensils with a child and not kissing a child on the lips. Attitude was assessed using a seven-point semantic differential scale with four different descriptors: impractical-practical, inconvenientconvenient, difficult-easy, unrealistic-realistic [17]. Ratings were averaged over the four scales to create a single attitude score for each CMV prevention behavior ranging from 1 to 7 with higher scores indicating more positive attitudes toward performing that behavior.

Independent variables included demographics, background knowledge of CMV, past participation in CMV prevention behaviors, parental affection, perceived behavioral control, and subjective norms.

Demographic questions included educational level, annual household income, race, ethnicity, marital status, employment status, health insurance, pregnancy status, number of children at home, and household 
crowding index. Crowding was categorized as high ( $>1$ person/room) or average/low ( $<1$ person/room) [19]. Average and low were combined as few people $(n=53)$ in the sample met the definition of low crowding. Household income was converted into percentage of the federal poverty level (FPL) using household size and categorized as $<100 \%$ FPL, 100$200 \%$ FPL, and $>200 \%$ FPL [20]. Two questions served as proxy measures for acculturation for Hispanic respondents: country of birth and the language spoken most often at home.

CMV background knowledge was measured by 11 items [16]. Response options were true, false and I don't know. These items were coded as 1 if correct and 0 otherwise and summed to create a knowledge score (Cronbach's alpha 0.92). Participation in behaviors that increase CMV risk was measured by asking about the frequency of engaging in four behaviors: sharing food, cups and utensils and kissing children on the lips [16].

Perceived behavioral control was measured by two items adapted from Yardley, Miller, Schlotz, and Little [21]. The questions asked about their confidence that they could perform the prevention behaviors and if it was possible to perform these same behaviors. A combined perceived behavioral control score for avoiding the three sharing behaviors (Cronbach's alpha $=0.92$ ) was created as a separate score for avoiding kissing a child on the lips (Cronbach's alpha $=0.89$ ).

Parental affection was measured with items adapted from the Parenting Styles and Dimensions Questionnaire [22]. Each of the three items used the question stem "I express affection by..." and inquired about the frequency of "hugging", "kissing" or "holding" their child. Responses were on a 5-point scale. Few women responded "never" or "once in a while" to these questions so the variable was recoded into three categories: always, very often and not often.

Subjective norms toward the CMV prevention behaviors were measured by four questions adapted from Steele and Porche [23]. Respondents were asked to rate their level of agreement that most people who are important to them or whose opinion they value a) practice the target behaviors and b) think that she should engage in the target behaviors. During questionnaire pre-testing, we learned that people who are important to them or whose opinion they value are not limited to women rearing children and therefore they are not practicing the CMV prevention behaviors. Thus, after pre-testing we eliminated that aspect of the standard normative belief questions. We calculated a subject norms score for the three sharing behaviors (Cronbach $\alpha=0.95$ ) and beliefs toward kissing a child on the lips (Cronbach $\alpha=0.89$ ).

\section{Statistical analysis}

Frequencies and proportions for categorical variables were calculated to describe the demographic characteristics of the sample. Statistical differences between Hispanic and non-Hispanic women were determined using a chi-square test for the difference in proportions. Means and 95\% confidence intervals were calculated for frequency of participation in CMV risk behaviors, attitudes scales, perceived behavioral control, and subjective norms scales. T-test and ANOVA were used to evaluate differences in means between subgroups of Hispanic women (those born in the U.S. and the primary language spoken at home) and between Hispanic and nonHispanic women.

Factor analysis confirmed findings from previous work [17] which indicated that attitudes toward CMV prevention behaviors cluster by behavior type. Thus, women's attitudes toward the CMV prevention behaviors were assessed using average scores from semantic-differential scales for the collective sharing behaviors (12 items) and for kissing behavior (4 items).

Linear regression was used to examine associations between demographic and behavioral variables. Two models (one each for sharing and kissing) were created for the primary outcome of attitudes toward CMV prevention behaviors. As we hypothesized that perceived behavioral control and frequency of performing CMV risk behaviors would be important predictors of attitudes, we also constructed regression models to assess predictors of these constructs for each behavior group. All six regression models included the following independent variables: ethnicity, age of youngest child at home, maternal age and education level, marital status, level of household crowding, whether the respondent was pregnant or planning a pregnancy, familiarity with CMV, subjective norms and parental affection. Models assessing perceived behavioral control also controlled for frequency of performing CMV risk behaviors. Models assessing attitudes also controlled for frequency of performing CMV risk behaviors and perceived behavioral control. Models were constructed using manual backward elimination. Covariates that did not reach significance at $\alpha=0.10$ were excluded. If any pre-survey frequency of a sharing behavior reached significance in the model, all three were retained. All analyses were completed in SAS 9.4 (SAS Institute Inc., Cary, NC, USA).

\section{Results}

The sample included 405 Hispanic and 413 nonHispanic women. Demographic characteristics of the sample are given in Table 1. The non-Hispanic sample was $97.6 \%$ white or Caucasian. 
Table 1 Demographics of Sample

\begin{tabular}{|c|c|c|c|}
\hline & $\begin{array}{l}\text { Hispanic } \\
N=405\end{array}$ & $\begin{array}{l}\text { Non-Hispanic } \\
N=413\end{array}$ & $\begin{array}{l}\text { Chi-Square } \\
p \text {-value }\end{array}$ \\
\hline & \multicolumn{3}{|l|}{$n(\%)$} \\
\hline Mean Age in Year (SD) & $28.34(5.18)$ & $29.41(5.03)$ & 0.003 \\
\hline \multicolumn{4}{|l|}{ Youngest Child at Home } \\
\hline Less than a Year & $110(27.16)$ & $89(21.55)$ & \multirow[t]{5}{*}{0.29} \\
\hline 1 Year old & $99(24.44)$ & $121(29.30)$ & \\
\hline 2 years old & $75(18.52)$ & 78 (18.89) & \\
\hline 3 years old & $60(14.81)$ & $55(13.32)$ & \\
\hline 4 or 5 years old & $61(15.06)$ & $70(16.95)$ & \\
\hline \multicolumn{4}{|l|}{ Highest Education Received } \\
\hline High School Graduate, GED, or less & $94(23.21)$ & $97(23.49)$ & \multirow[t]{3}{*}{0.55} \\
\hline Some College or Associate Degree & $201(49.63)$ & $191(46.25)$ & \\
\hline College Graduate or Post Graduate Degree & $110(27.16)$ & $125(30.27)$ & \\
\hline \multicolumn{4}{|l|}{ Income as a Percentage of Federal Poverty Level } \\
\hline$<100 \% \mathrm{FPL}$ & $98(24.32)$ & $80(19.37)$ & \multirow[t]{3}{*}{0.06} \\
\hline $100-200 \% \mathrm{FPL}$ & $139(34.49)$ & $131(31.72)$ & \\
\hline$>200 \% \mathrm{FPL}$ & $166(41.19)$ & $202(48.91)$ & \\
\hline \multicolumn{3}{|l|}{ Marital Status } & \multirow[t]{3}{*}{0.002} \\
\hline Married or Member of unmarried couple & $309(76.30)$ & $351(84.99)$ & \\
\hline Widowed, Divorced, Separated, Unmarried & $96(23.70)$ & $62(15.01)$ & \\
\hline \multicolumn{3}{|l|}{ Pregnancy Status } & \multirow[t]{4}{*}{0.9221} \\
\hline Not pregnant or planning a pregnancy & $298(73.58)$ & $308(74.58)$ & \\
\hline Planning a pregnancy within 12 months & $81(20)$ & $78(18.89)$ & \\
\hline Currently pregnant & $26(6.42)$ & $27(6.54)$ & \\
\hline \multicolumn{3}{|l|}{ Crowding } & \multirow[t]{3}{*}{$<.0001$} \\
\hline High & $131(32.35)$ & $47(11.38)$ & \\
\hline Average/Low & $274(67.65)$ & $366(88.62)$ & \\
\hline
\end{tabular}

Hispanic and non-Hispanic women were similar with respect to many demographic characteristics. However, the average age of Hispanic women was slightly younger than non-Hispanic women, Hispanic women were less likely to be married or part of an unmarried couple and Hispanic women were more likely to report living in a home with high levels of crowding (32.4\% vs. 11.4\%; $p<.0001)$. Among Hispanic women, $88 \%$ were born in the U.S. The majority of Hispanic women (59\%) identified as Mexican, Mexican American, or Chicana while16.8\% identified as Puerto Rican. The remaining $24 \%$ identified as "other" Hispanic or Latina origin. Among all Hispanics, 55\% reported speaking mostly English in their homes, while $37 \%$ reported speaking English and Spanish equally in their homes.

Approximately $13 \%$ of the overall sample reported that they were very familiar or somewhat familiar with CMV. Hispanic women reported higher levels of CMV awareness (Hispanic 16.8\% vs. non-Hispanic 9.7\%; $p=0.002$ ).
Among women who reported familiarity with CMV ( $n=$ 108) Hispanic women had a higher, but non-significant, score on the knowledge scale $\left(M_{\text {Hispanic }}=4.40 ; M_{\text {non-His- }}\right.$ panic $=3.78 ; p=0.23)$. Pre-survey participation in CMV risk behaviors is given in Table 2. Non-Hispanic women reported more frequent participation for two risk behaviors: sharing eating utensils and kissing a child on the lips, as compared to Hispanic women.

Both Hispanic and non-Hispanic women reported generally positive attitudes toward CMV prevention behaviors (see Fig. 1 and Additional file 1). However, Hispanic women reported more positive attitudes than nonHispanic women. The mean attitude score for avoiding sharing behaviors was 5.55 for Hispanic women compared to 5.20 in non-Hispanic women $(p=0.002)$. Similarly, Hispanic women had a mean score of 4.80 for attitudes toward avoiding kissing a child on the lips, compared to 4.21 in non-Hispanic women $(p=.0002)$. For both groups, attitudes were significantly lower 
Table 2 Self-Reported pre-survey frequency of participation in select cytomegalovirus (CMV) risk behaviors ${ }^{\mathrm{a}}$

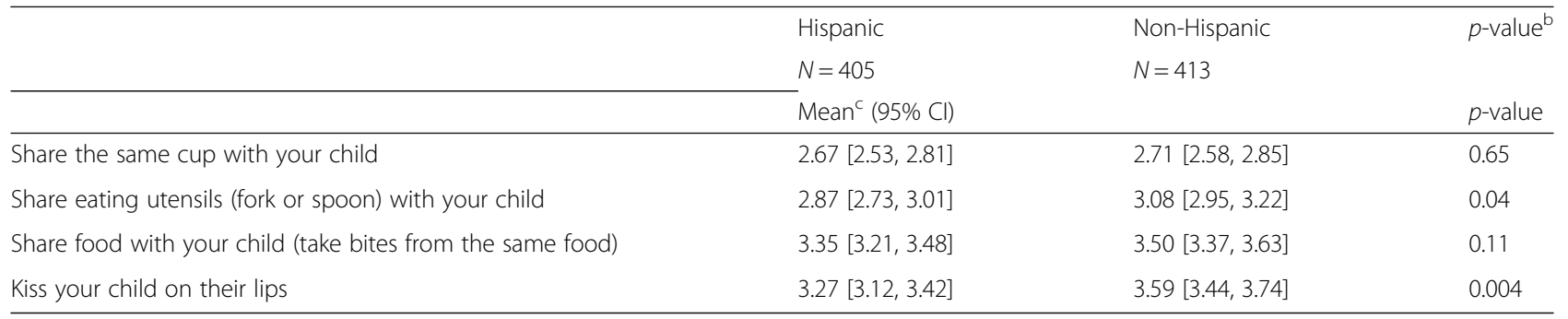

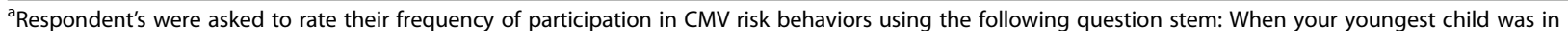
diapers how often did you do each of the following? (If your youngest child is still in diapers, think about what you currently do)

${ }^{\mathrm{b}} p$-values derived from a t-test for the difference in means between Hispanic and non-Hispanic respondents

${ }^{\mathrm{c}}$ Frequency of behaviors were reported on a 5 -point Likert scale where $1=$ Never and $5=$ every day. Higher mean values indicate greater frequency of participation in CMV risk behaviors

toward avoiding kissing than attitudes toward avoiding sharing behaviors $(p<.0001)$.

Among Hispanic women, U.S. born Hispanics reported kissing their child on the lips $\left(M_{\text {U.SBorn }}=3.35\right.$ vs. $M_{\text {Bor- }}$ nOutsideu.s. $=2.65 ; p=0.005)$ and sharing food, cups and eating utensils $\left(M_{\text {U.SBorn }}=3.05\right.$ vs. $M_{\text {BornOutsideU.S. }}=2.62$; $p=0.03)$ more frequently than did Hispanic women born outside of the U.S. Hispanic women who reported speaking mostly Spanish in their homes also reported lower frequency of kissing a child on the lips $\left(M_{\text {Spanish }}=\right.$ 2.65, $\left.M_{\text {English ESpanish }}=2.97, M_{\text {English. }}=3.56 ; p=.0005\right)$ compared to Hispanic women who spoke mostly English or English and Spanish equally at home. Similarly, those would spoke mostly Spanish at home had more positive attitudes toward avoiding kissing children on the lips than those who spoke English mostly, or English and Spanish equally $\left(M_{\text {Spanish }}=5.92, M_{\text {English ESpanish }}=5.45\right.$, $\left.M_{\text {English. }}=4.20 ; p<.0001\right)$ and reported higher perceived behavioral control $\left(M_{\text {Spanish }}=6.05, M_{\text {English } \& \text { Spanish }}=5.37\right.$, $\left.M_{\text {English. }}=4.81 ; p=.0005\right)$.

Women of both groups reported high mean levels of perceived behavioral control for avoiding sharing food, cups, and utensils with their children $\left(M_{\text {Hispanic }}=5.72\right.$; $\left.M_{\text {non-Hispanic }}=5.64 ; p=0.40\right)$. Perceived behavioral control for not kissing a child on the lips was lower than for sharing behaviors in both groups. However, Hispanic women $(M=5.11)$ reported significantly higher perceived behavioral control for avoiding kissing on the lips than non-Hispanic women $(M=4.63 ; p=0.001)$.

There were differences in how the two groups of women showed affection to their children. The majority of women in the sample reported that they kissed, hugged or held their children to show affection "always." An estimated $84.4 \%$ of Hispanic women reported they "always" hugged their children to show affection compared to $75.5 \%$ of non-Hispanic women $(p=0.004)$. Similarly, a higher percentage of Hispanic women kissed (72.4\% vs. $56.9 \% ; p<.0001)$ and held $(71.1 \%$ vs. $55.2 \%$; $p<.0001)$ their children "always" as compared to nonHispanic women. The question about how affection was expressed asked about kissing in general, and not about the location of the kiss.

For both groups of women, the plurality reported that they neither agreed nor disagreed that that people important to them and whose opinions they valued thought they should share food, cups, and utensils (Table 3).

Results of the regression models are given in Table 4. Increased frequency of sharing food, cups, or utensils was associated with having children between ages 1-5, having a high school education or less increasing maternal age, being pregnant or planning a pregnancy, increased perception that others expected sharing behaviors (subjective norms) and higher levels of parental affection. Similarly, increased frequency of kissing a child on the lips was associated with increased subjective norms and increased parental affection. For both avoiding sharing behaviors and avoiding kissing a child on the lips, increased perception that others expected the behaviors and increased frequency of performing the risk behaviors were associated with decreased perceived behavioral control.

More positive attitudes toward avoiding sharing food, cups, and utensils with a child were significantly associated with Hispanic ethnicity, having an older (4 to 5 year-old) child, a high school education, higher levels of perceived behavioral control, and above average household crowding. Additionally, less positive attitudes toward avoiding sharing behaviors were associated with higher levels of subjective norms and increased presurvey frequency of sharing cups or utensils. Nearly half of the variation in attitudes toward sharing behaviors was explained by the final model $\left(r^{2}=0.49\right)$. Attitudes toward not kissing a child on the lips showed a similar pattern, familiarity with CMV was associated with an increase in positive attitudes toward behavior change as were increased perceived behavioral control and higher household crowding. Conversely, increased pre-survey frequency of kissing a child on the lips and increased perception that others expected that they kiss a child on the lips were associated with less positive attitudes 


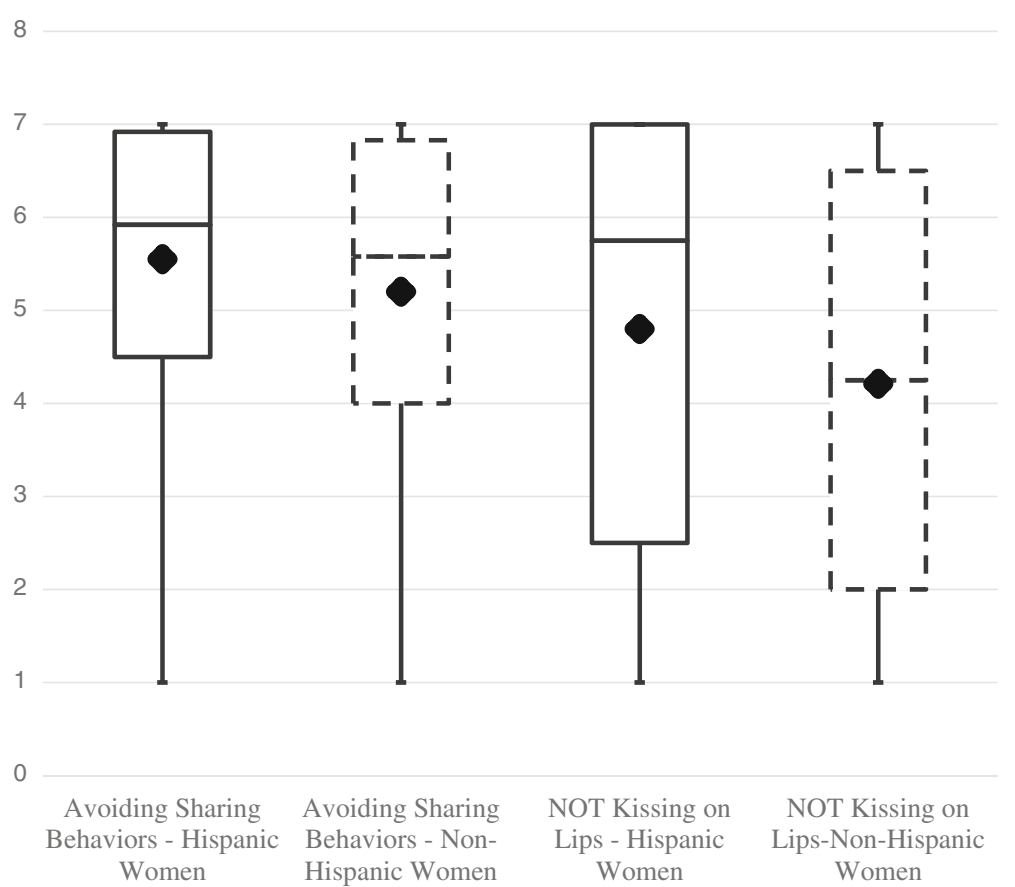

Fig. 1 Hispanic and non-Hispanic women's attitudes toward not kissing on lips and avoiding sharing behaviors. Attitudes toward CMV prevention behaviors were assessed by asking women to rate on four 7-point semantic differential scales: impractical (1) to practical (7), inconvenient (1) to convenient (7), difficult (1) to easy (7) and unrealistic (1) to realistic (7) for each of the CMV prevention behaviors. Higher values indicate that women viewed the behaviors are more practical, more convenient, easier and more realistic. Overall attitudes toward kissing on the lips was calculated as the average of the four adjectives. Overall attitude for the sharing behaviors (sharing a cup, sharing eating utensils, and sharing food with a child) were calculated into a single scale as the average of the four adjectives. Box plots summarize the distribution of attitudes across the behaviors: median (diamond shape), interquartile range (25th and 75th percentiles), and range (minimum and maximum)

toward behavior change. Most the variation $\left(\mathrm{r}^{2}=0.60\right)$ in attitudes toward avoiding kissing a child on the lips was explained by the final model (model \#6).

\section{Discussion}

The purpose of this research was to understand Hispanic and non-Hispanic women's attitudes toward CMV prevention behavior. We also examined the association between attitudes, subjective norms and perceived behavioral control. This is the first research that has focused specifically on Hispanic women. Hispanic women reported engaging in CMV risk behaviors less often than non-Hispanic women. There were also betweengroup differences in attitudes, perceived behavioral control and subjective norms. Ethnicity was a significant predictor in only one of six regression models indicating that other factors, like subjective norms and perceived behavioral control are more important in predicting attitudes than ethnicity.

CMV awareness rates in both groups were similar to other research [13, 17]. Similarly, low rates of CMV knowledge, of transmission modes, and the frequency of participating in CMV prevention and risk behaviors was similar to other research that used a national sample of women $[13,16,17]$.
Although CMV prevalence is higher among Hispanics than non-Hispanics, certain behavioral risk factors for CMV may be less common among Hispanic women as was found in the present study. Similarly, a study comparing the prevalence of risk factors for oral bacteria transmission observed that Hispanic parents were less likely to kiss their children on the lips, share food and utensils with their children, and put their toddler's pacifier in their own mouth [24]. However, other researchers have suggested that differences in infection rates between ethnic groups may be due to household crowding [19]. In our study, Hispanic women were living in higher density housing than non-Hispanic women.

For CMV behavior modification to occur, a woman must believe that she is in control of performing the recommended behavior [25]. Women reported high levels of perceived behavioral control for avoiding sharing behaviors; scores were somewhat lower for not kissing a child on the lips. These levels of perceived behavioral control are similar to other research we have conducted [17].

In the present study, Hispanic women reported kissing to show affection more often than non-Hispanic women, yet they reported kissing on the lips less often than nonHispanic women. This was particularly true for Hispanic women who were foreign born or reported speaking 
Table 3 Subjective norms for select CMV risk behaviors in Hispanic and non-Hispanic women

\begin{tabular}{|c|c|c|c|c|c|c|}
\hline & $\begin{array}{l}\text { Hispanic } \\
N=413\end{array}$ & $\begin{array}{l}\text { Non-Hispanic } \\
N=405\end{array}$ & $p$-value ${ }^{a}$ & $\begin{array}{l}\text { Hispanic } \\
N=413\end{array}$ & $\begin{array}{l}\text { Non-Hispanic } \\
N=405\end{array}$ & $p$-value ${ }^{a}$ \\
\hline & \multicolumn{3}{|c|}{ People who are important to me think I should: } & \multicolumn{3}{|c|}{ People whose opinion I value think I should: } \\
\hline & $n(\%)$ & $n(\%)$ & & $n(\%)$ & $n(\%)$ & \\
\hline \multicolumn{7}{|c|}{ Share the same cup with my child } \\
\hline Strongly agree & $24(5.93)$ & $20(4.84)$ & 0.02 & $32(7.9)$ & $17(4.12)$ & $<.0001$ \\
\hline Somewhat agree & $58(14.32)$ & $43(10.41)$ & & $56(13.83)$ & $39(9.44)$ & \\
\hline Neither agree nor disagree & $162(40.00)$ & $207(50.12)$ & & $150(37.04)$ & $214(51.85)$ & \\
\hline Somewhat disagree & $47(11.60)$ & $54(13.08)$ & & $49(12.10)$ & $58(14.04)$ & \\
\hline Strongly disagree & $114(28.15)$ & $89(21.55)$ & & $118(29.14)$ & $85(20.58)$ & \\
\hline Share eating utensils & & & 0.19 & & & \\
\hline Strongly agree & $24(5.94)$ & $22(5.33)$ & & $34(8.40)$ & $20(4.84)$ & 0.003 \\
\hline Somewhat agree & $61(15.10)$ & $49(11.86)$ & & $52(12.84)$ & $49(11.86)$ & \\
\hline Neither agree nor disagree & $164(40.59)$ & $200(48.43)$ & & $153(37.78)$ & $210(50.85)$ & \\
\hline Somewhat disagree & $55(13.61)$ & $57(13.8)$ & & $63(15.56)$ & $51(12.35)$ & \\
\hline Strongly disagree & $100(24.75)$ & $85(20.58)$ & & $103(25.43)$ & $83(20.10)$ & \\
\hline Share food with my child & & & 0.04 & & & \\
\hline Strongly agree & $39(9.63)$ & $37(8.96)$ & & $43(10.62)$ & $28(6.78)$ & 0.02 \\
\hline Somewhat agree & $88(21.73)$ & $66(15.98)$ & & 79 (19.51) & $73(17.68)$ & \\
\hline Neither agree nor disagree & $159(39.26)$ & $198(47.94)$ & & $155(38.27)$ & $197(47.7)$ & \\
\hline Somewhat disagree & $37(9.14)$ & $46(11.14)$ & & $41(10.12)$ & $49(11.86)$ & \\
\hline Strongly disagree & $82(20.25)$ & $66(15.98)$ & & $87(21.48)$ & $66(15.98)$ & \\
\hline Kiss my child on the lips & & & $<.0001$ & & & \\
\hline Strongly agree & $70(17.28)$ & $77(18.64)$ & & $69(17.04)$ & $72(17.43)$ & $<.0001$ \\
\hline Somewhat agree & $54(13.33)$ & $71(17.19)$ & & $50(12.35)$ & $86(20.82)$ & \\
\hline Neither agree nor disagree & $131(32.35)$ & $166(40.19)$ & & 137 (33.83) & $154(37.29)$ & \\
\hline Somewhat disagree & $38(9.38)$ & $43(10.41)$ & & $31(7.65)$ & $38(9.20)$ & \\
\hline Strongly disagree & $112(27.65)$ & $56(13.56)$ & & $118(29.14)$ & $63(15.25)$ & \\
\hline
\end{tabular}

${ }^{a} p$-value derived from a chi-square test for the difference of proportions for Hispanic vs. non-Hispanic women

mostly Spanish in their homes. Being foreign born and/ or speaking primarily Spanish in the home may indicate less acculturation. This tendency to be more expressive may be based in culture, as Hispanic women are more apt to engage in more frequent and close touch [26]. A study of European Americans and Mexican Americans showed that persons who identified as less acculturated and more connected to their heritage were more comfortable with affectionate touch [27]. Though that study did not assess kissing specifically it suggests that Hispanic culture is more demonstrative than other Anglo/ European cultures. Though in the present study Hispanic women respondents reported being more demonstrative to their child, they believed they had more control to not kiss on the lips than did non-Hispanic white women. Again, this may represent cultural differences in way affection is expressed and is consistent with our finding that Hispanic women kiss their children on the lips less frequently.
Women with more positive attitudes toward the CMV prevention behaviors also were more confident in their ability to not share cups, food or utensils, and to not kiss on the lips. Although both groups of women held generally positive attitudes toward the CMV prevention behaviors, scores were lower for not kissing a child on the lips. The tendency to have less positive attitudes toward not kissing on the lips than other prevention behaviors is similar to past research completed with a U.S. panel of women [17]. Overall, there are between group differences as Hispanic women have more positive attitudes than non-Hispanic toward the CMV prevention behaviors. This may be because they reportedly do these behaviors less often than non-Hispanic women do. Women who perceived that others expected them to engage in kissing on the lips and sharing behaviors had decreased attitudes scores. The final regression models explained a substantial amount of the variation in attitudes toward the CMV prevention behaviors. 
Table 4 Factors associated with CMV risk behaviors, perceived behavior control and attitudes toward CMV prevention behaviors

\begin{tabular}{|c|c|c|c|c|c|c|}
\hline & Model 1 & Model 2 & Model 3 & Model 4 & Model 5 & Model 6 \\
\hline \multirow[t]{2}{*}{ Variable } & $\begin{array}{l}\text { Frequency } \\
\text { of Sharing }\end{array}$ & $\begin{array}{l}\text { Frequency } \\
\text { of Kissing }\end{array}$ & $\begin{array}{l}\text { Perceived Behavioral } \\
\text { Control: NOT Sharing }\end{array}$ & $\begin{array}{l}\text { Perceived Behavioral } \\
\text { Control: NOT Kissing }\end{array}$ & $\begin{array}{l}\text { Attitudes } \\
\text { toward NOT } \\
\text { sharing }\end{array}$ & $\begin{array}{l}\text { Attitudes toward NOT } \\
\text { Kissing on the Lips }\end{array}$ \\
\hline & $\beta$ (SE) & & & & & \\
\hline Hispanic & & & & & $0.20(0.08)^{*}$ & \\
\hline Familiar with CMV & & & & & $0.22(0.12)$ & $0.32(0.15)^{*}$ \\
\hline \multicolumn{7}{|l|}{ Age of youngest child at home } \\
\hline $4-5$ years & $0.47(0.13)^{* *}$ & & & & $0.46(0.13)^{* *}$ & \\
\hline 3 years & $0.60(0.13)^{* * *}$ & & & & $0.14(0.14)$ & \\
\hline 2 years & $0.57(0.12)^{* * *}$ & & & & $0.08(0.13)$ & \\
\hline 1 year & $0.82(0.11)^{* * *}$ & & & & $-0.09(-0.12)$ & \\
\hline$<1$ year & Ref & & & & Ref & \\
\hline \multicolumn{7}{|l|}{ Education } \\
\hline$\leq$ High School Graduate & $0.35(0.11)^{*}$ & & & & $0.24(0.12)^{*}$ & \\
\hline Some College & $0.13(0.09)$ & & & & $0.08(0.10)$ & \\
\hline College Graduate or Above & Ref & & & & Ref & \\
\hline Pregnant or Planning a Pregnancy & $0.18(0.09)^{*}$ & & & & & \\
\hline Mother's Age in Years & $0.02(0.001)^{*}$ & & & & & \\
\hline \multicolumn{7}{|l|}{ Marital Status } \\
\hline Married/Unmarried Couple & & $0.19(0.11)$ & $0.27(.06, .49)$ & & & \\
\hline $\begin{array}{l}\text { Never Married/Widowed/ } \\
\text { Separated/Divorced }\end{array}$ & & Ref & Ref & & & \\
\hline \multicolumn{7}{|l|}{ Household Crowding } \\
\hline High Crowding & & & & & $0.21(0.10)^{*}$ & $0.27(0.12)^{*}$ \\
\hline Average or Low Crowding & & & & & Ref & Ref \\
\hline $\begin{array}{l}\text { Subjective Norms for Sharing } \\
\text { Behaviors }\end{array}$ & $0.47(0.04)^{* * *}$ & & $-0.33(0.05)^{* * *}$ & & $-0.24(0.04)^{* * *}$ & \\
\hline $\begin{array}{l}\text { Subjective Norms for Kissing } \\
\text { on Lips }\end{array}$ & & $0.67(0.04)^{* * *}$ & & $-0.38(0.05)^{* * *}$ & & $-0.25(0.05)^{* * *}$ \\
\hline Parental Affection & $0.29(0.9)^{* *}$ & $0.44(0.10)^{* * *}$ & & & & \\
\hline $\begin{array}{l}\text { Perceived Behavioral Control for } \\
\text { Avoiding Sharing Behaviors }\end{array}$ & & & & & $0.55(0.3)^{* * *}$ & \\
\hline $\begin{array}{l}\text { Perceived Behavioral Control for } \\
\text { Avoiding Kissing on the Lips }\end{array}$ & & & & & & $0.53(0.03)^{* * *}$ \\
\hline Frequency of Sharing Food & & & $-0.14(0.05)^{*}$ & & $-0.05(-0.05)$ & \\
\hline Frequency of Sharing a Cup & & & $-0.06(0.05)$ & & $-0.13(-0.04)^{*}$ & \\
\hline Frequency of Sharing Utensils & & & $-0.11(0.05)^{*}$ & & $-0.11(-0.05)^{*}$ & \\
\hline $\begin{array}{l}\text { Frequency of Kissing a Child on } \\
\text { the Lips }\end{array}$ & & & & $-0.59(0.04)^{* * *}$ & & $-0.42(0.04)^{* * *}$ \\
\hline$r^{2}$ & 0.25 & 0.32 & 0.20 & 0.39 & 0.49 & 0.60 \\
\hline
\end{tabular}

${ }^{*} p<.05 ;{ }^{* *} p<.01 ;{ }^{* * *} p<.0001$

It appears that women more frequently engaged in kissing on the lips and the sharing behaviors when they felt a social expectation to do so. Each culture has a "social code" for how an adult is expected to behave in relation to their child [28]. In this study, an increased social expectation was also associated with lower levels of perceived behavior control. Women may feel that it is difficult to believe they can change a behavior when they do the behavior frequently and perceive that others expect them to do it as well. Although subjective norms were influential, there was a moderate proportion of women who neither agreed nor disagreed with the subjective norms statements. It could be that these CMV prevention behaviors are 
not frequently discussed verbally, but rather acceptable behavior is assumed.

\section{Limitations}

This is a cross-sectional descriptive study with selfreport data, which may be subject to recall bias and social desirability bias. Though we did not provide any CMV-related educational material about the behaviors that increase CMV risk, it is possible that the wording of the questions implied the preferred behavior. Therefore, it is probable that all responses reflect a degree of social desirability bias. The difference between Hispanic and non-Hispanic women's responses might be attributable to cultural differences in the influence of social desirability. Research has shown that responses vary by culture and Hispanics tend to be influenced more by social desirability [29-31].

This is national sample using an on-line panel. The data may not reflect all women of childbearing years. However, our demographic data are similar to other national studies of CMV awareness and attitudes $[9,16]$. The measure of attitudes was developed by the authors and has been used in prior research. While reliability estimates are available, validity evidence is not. Finally, this survey was taken in English, 88\% of the sample was born in the U.S. and therefore may not represent all Hispanic women, particularly those who have recently come to the U.S. or are not fluent in English. As Hispanic women are at increased risk of congenital CMV infection, additional research should consider the inclusion of recent immigrants and non-English speaking Hispanics.

\section{Conclusion}

Research has shown that communicating with women to reduce CMV infection can be effective $[11,32]$. In the current study, women expressed positive attitudes toward the CMV prevention behaviors and feel that they can do them. These data suggest that while there may be ethnic differences in attitudes toward CMV prevention behaviors between Hispanic women and non-Hispanic women of childbearing age, that subjective norms and perceived behavior control are more important predictors of attitudes than ethnicity. In developing strategic efforts to increase women's participation in CMV prevention behaviors, a focus on understanding what is influencing subjective norms and feelings of control over the behavior, may be warranted.

\section{Additional file}

Additional file 1: Hispanic \& non-Hispanic women's attitudes toward individual CMV prevention behaviors. Table that shows Hispanic and non-Hispanic women's attitudes toward four CMV prevention behaviors. (DOCX $16 \mathrm{~kb})$

\section{Abbreviations}

CMV: Cytomegalovirus; FPL: Federal poverty level

\section{Funding}

Funding was provided from internal university funds. The funding body had no role in the design of the study and collection, analysis, and interpretation of data and in writing the manuscript.

\section{Availability of data and materials}

Data upon which the analysis is based is available upon reasonable request from the authors. Institutional review board approval did not grant permission to post data publicly.

\section{Authors' contributions}

RT designed the study, coordinated data collection, and prepared the manuscript. BMM designed the study, conducted data analysis, and prepared the manuscript. EB assisted with study design, data analysis, and preparing the manuscript. NNN assisted with study design, data analysis, and preparing the manuscript. RJB assisted with study design, data analysis, and preparing the manuscript. All authors read and approved the final manuscript.

Ethics approval and consent to participate

The study was approved by the Brigham Young University institutional review board and assigned study number 16479. A consent document was provided on the screen when respondents began the on-line survey; consent was implied when the participant completed the survey.

\section{Competing interests}

The authors declare that they have no competing interests.

\section{Publisher's Note}

Springer Nature remains neutral with regard to jurisdictional claims in published maps and institutional affiliations.

\section{Author details}

'Department of Health Science, Brigham Young University, Provo, UT, USA. ${ }^{2}$ Department of Epidemiology and Biostatistics, University of South Florida, Tampa, FL, USA.

Received: 18 January 2018 Accepted: 30 April 2018

Published online: 24 May 2018

\section{References}

1. Centers for Disease Control and Prevention: Cytomegalovirus and Congenital CMV infection. https://www.cdc.gov/cmv/overview.html (2017) Accessed18 Jan 2018.

2. Wreghitt TG, Teare EL, Sule O, Devi R, Rice P. Cytomegalovirus infection in immunocompetent patients. Clin Infect Dis. 2003;37:1603-6.

3. Picone O, Vauloup-Fellous C, Cordier AG, Guitton S, Senat MV, Fuchs F, Ayoubi JM, Grangeot Keros L, Benachi A. A series of 238 cytomegalovirus primary infections during pregnancy: description and outcome. Prenat Diagn. 2013;33:751-8.

4. Kenneson A, Cannon MJ. Review and meta-analysis of the epidemiology of congenital cytomegalovirus (CMV) infection. Rev Med Virol. 2007;17:253-76.

5. Dollard SC, Grosse SD, Ross DS. New estimates of the prevalence of neurological and sensory sequelae and mortality associated with congenital cytomegalovirus infection. Rev Med Virol. 2007;17:355-63.

6. Fowler KB, Pass RF. Risk factors for congenital cytomegalovirus infection in the offspring of young women: exposure to young children and recent sexual activity. Pediatrics. 2006;118:e286-92.

7. Hyde TB, Schmid DS, Cannon MJ. Cytomegalovirus seroconversion rates and risk factors: implications for congenital CMV. Rev Med Virol. 2010;20:311-26.

8. Cannon MJ, Hyde TB. Schmid DS review of cytomegalovirus shedding in bodily fluids and relevance to congenital cytomegalovirus infection. Rev Med Virol. 2011;21(4):240-55.

9. Cannon MJ, Griffiths PD, Aston V, Rawlinson WD. Universal newborn screening for congenital CMV infection: what is the evidence of potential benefit. Rev Med Virol. 2014;24:291-307.

10. Cannon MJ, Davis KF. Washing our hands of the congenital cytomegalovirus disease epidemic. BMC Public Health. 2005;5:70 https://doi.org/10.1186/1471-2458-5-70 
11. Revello MG, Tibaldi C, Masuelli G, Frisina V, Sacchi A, Furione M, Arossa A, Spinillo A, Klersy C, Ceccarelli M, Gerna G, Todors T. Prevention of primary cytomegalovirus infection in pregnancy. EBioMedicine. 2015;2:1205-10.

12. Lanzieri TM, Kruszon-Moran D, Amin MM, Bialek SR, Cannon MJ, Dollard SC. Seroprevalence of cytomegalovirus among children 1 to 5 years of age in the United States from the National Health and Nutrition Examination Survey of 2011 to 2012. Clin Vaccine Immunol. 2015;22:245-7.

13. Cannon MJ, Westbrook K, Levis D, Schleiss MR, Thackeray R, Pass RF. Awareness of and behaviors related to child-to-mother transmission of cytomegalovirus. Prev Med. 2012;54:351-7.

14. Aizen I, Fishbein M. The influence of attitudes on behavior. In: Albarracín D, Johnson BT, Zanna MP, editors. The handbook of attitudes. Mahwah, NJ: Lawrence Erlbaum Associates; 2005. p. 173-221.

15. Godin G, Kok G. The theory of planned behavior: a review of its applications to health-related behaviors. Am J of Health Promotion. 1996;11:87-98.

16. Price SM, Bonilla E, Zador P, Levis DM, Kilgo CL, Cannon MJ. Educating women and congenital cytomegalovirus: assessment of health education materials through a web-based survey. BMC Women's Health. 2014;14:144.

17. Thackeray R, Magnusson BM. Women's attitudes toward practicing cytomegalovirus prevention behaviors. Preventive Medicine Reports. 2016;4: $517-24$.

18. Aday LA, Cornelius LJ. Designing and conducting health surveys: a comprehensive guide. Hoboken NJ: John Wiley \& Sons; 2006.

19. Bate SL, Dollard SC, Cannon MJ. Cytomegalovirus seroprevalence in the United States: the National Health and Nutrition Examination Surveys, 1988-2004. Clin Infect Dis. 2010:50:1439-47.

20. US Department of Health and Human Services: Federal Poverty Guidelines Used to Determine Financial Eligibility for Certain Federal Programs. https://aspe.hhs.gov/poverty-guidelines (2017). Accessed 16 Jan 2018.

21. Yardley L, Miller S, Schlotz W, Little P. Evaluation of a web-based intervention to promote hand hygiene: exploratory randomized controlled trial. J Med Internet Res. 2011;13:e107.

22. Robinson CC, Mandleco B, Olsen SF, Hart CH. Authoritative authoritarian and permissive parenting practices: development of a new measure. Psychol Rep. 1995;7:819-30

23. Steele S, Porche D. Questionnaire development to predict mammography intention among women in southeastern Louisiana. J Nurs Meas. 2005;13:23-37.

24. Eckert GJ, Jackson R, Fontana M. Sociodemographic variation of caries risk factors in toddlers and caregivers. International Journal of Dentistry. 2010. https://doi.org/10.1155/2010/593487

25. Ajzen I. The theory of planned behavior. Organ Behav Hum Decis Process. 1991;50(2):179-211.

26. Franco F, Fogel A, Messinger DS, Frazier CA. Cultural differences in physical contact between Hispanic and Anglo mother-infant dyads living in the United States. Early Development and Parenting. 1996;5:119-27.

27. Burleson MH, Roberts NA, Coon DW, Soto JA. Perceived cultural acceptability and comfort with affectionate touch: differences between Mexican Americans and European Americans. J Soc Pers Relat. 2018:1-23. https://doi.org/10.1177/0265407517750005.

28. Casati I. Hugging and embracing; kisses given kisses received. Preludes to tenderness between infant and adult. Early Child Dev Care. 1991;67:1-15.

29. Pole N, Best SR, Metzler T, Marmar CR. Why are Hispanics at greater risk for PTSD? Cult Divers Ethn Minor Psychol. 2005;11:144-61.

30. Warnecke RB, Johnson TP, Chavez N, Sudman S, O'rourke DP, Lacey L, Horm J. Improving question wording in surveys of culturally diverse populations. Ann Epidemiol. 1997;7:334-42.

31. Johnson TP, Van de Vijver FJ. Social desirability in cross-cultural research. In: Harkness J, van de Vijver FJR, editors. Cross-cultural survey methods. Hoboken NJ: John Wiley and Sons; 2003. p. 193-209.

32. Vauloup-Fellous C, Picone O, Cordier AG, Parent-du-Châtelet I, Senat MV, Frydman R, Grangeot-Keros L. Does hygiene counseling have an impact on the rate of CMV primary infection during pregnancy?: results of a 3-year prospective study in a French hospital. J Clin Virol. 2009;46:S49-53. https://doi.org/10.1016/j.jcv.2009.09.003

\section{Ready to submit your research? Choose BMC and benefit from:}

- fast, convenient online submission

- thorough peer review by experienced researchers in your field

- rapid publication on acceptance

- support for research data, including large and complex data types

- gold Open Access which fosters wider collaboration and increased citations

- maximum visibility for your research: over $100 \mathrm{M}$ website views per year

At BMC, research is always in progress.

Learn more biomedcentral.com/submissions 